Research Article

\title{
Calculation and Analysis of the Source Term of the Reactor Core Based on Multivariate Analysis of Variance
}

\author{
Tao Zhou $\mathbb{D}^{1,2}$ Peng Xu, ${ }^{2,3,4}$ Tian Qi, ${ }^{2,3,4}$ Xuemeng Qin, ${ }^{2,3,4}$ Juan Chen, ${ }^{2,3,4}$ \\ and Zhongguang $\mathrm{Fu}^{5}$ \\ ${ }^{1}$ School of Nuclear Energy and Environment, Southeast University, Nanjing 210096, China \\ ${ }^{2}$ Institute of Nuclear Thermal-hydraulic Safety and Standardization, Beijing, China \\ ${ }^{3}$ School of Nuclear Science and Engineering, North China Electric Power University, Beijing 102206, China \\ ${ }^{4}$ Beijing Key Laboratory of Passive Safety Technology for Nuclear Energy, North China Electric Power University, \\ Beijing 102206, China \\ ${ }^{5}$ Key Laboratory of Condition Monitoring and Control for Power Plant Equipment, North China Electric Power University, \\ Beijing 102206, China
}

Correspondence should be addressed to Tao Zhou; 101012636@seu.edu.cn

Received 22 April 2020; Revised 4 May 2021; Accepted 25 May 2021; Published 3 June 2021

Academic Editor: Arkady Serikov

Copyright (c) 2021 Tao Zhou et al. This is an open access article distributed under the Creative Commons Attribution License, which permits unrestricted use, distribution, and reproduction in any medium, provided the original work is properly cited.

The calculation of the core source term is affected by various factors, such as fuel consumption, enrichment, specific power, and operation mode. The activity of lanthanides, fission products, and the photon source strength were calculated using the ORIGEN program. The weights of each factor were calculated by multivariate analysis of variance. The results show that the radioactivity of actinides and fission products increased with the increase in fuel consumption. As enrichment increased, the radioactivity of fission products and actinides decreased. The radioactivity of fission products and actinides increased linearly with the change in specific power, with a correlation coefficient of 1 . The changes in fuel consumption and enrichment have little effect on low-energy photons, but significantly affected high-energy photons. The change in specific power has little effect on the photon generation of different energy groups. The operation mode has little effect on the radioactivity of the nucleus and fission products. Multivariate analysis of variance shows that specific power is the most influential factor, followed by enrichment; the least influential factor is fuel consumption.

\section{Introduction}

When a serious accident occurs in a nuclear power plant, a large number of radioactive fission products are released from the core due to meltdown, which will cause environmental pollution and casualties. The amount of core source terms directly affects the quantity released. Jia [1] analyzed the important actinides nuclides, fission product nuclides, and activation product nuclides and proposed a reasonable disposal plan. Liu and Zhu [2] proposed an analysis model of the minimum nuclear criticality accident source term and provided a related calculation method. Wheeler et al. [3] used Serpent 2 to calculate the fuel consumption of molten salt reactors and found that gas removal can affect many different fission products beyond the gaseous chemical group. Actinides were also affected, although not in any gaseous fission product decay chain. Sun et al. [4] used MELCOR to study the source term estimation of an AP1000 nuclear power plant under severe accident conditions. Lee and Ko [5] developed a method to quantify the source term in each source term category identified in the level II probabilistic safety assessment analysis of nuclear power plants; then, the obtained source term characteristics were compared with other source terms. Liu et al. [6] conducted a series of experiments on the ${ }^{14} \mathrm{C}$ source term of a $10 \mathrm{MW}$ high-temperature gas-cooled reactor. Through a sensitivity study of the total porosity, open porosity, and open porosity of the matrix graphite after irradiation, their influence on ${ }^{14} \mathrm{C}$ activity concentrations in the 
primary coolant and in various deduction methods was clarified. Fang et al. [7] carried out ab initio calculations of the antineutrino flux of a new isotope reactor and provided accurate numerical calculations of the lepton wave function. Their results showed that the accumulated antineutrinos were within the range of high-energy antineutrinos, and the electron and electron energy spectra have significant but opposite spectral deviations in the range of $2 \%-4 \%$. Yang et al. [8] introduced the analysis method, scope, and main operating procedures of the source items following the Qinshan Nuclear Power Plant accident and calculated the release, migration, and distribution of nuclides under the design-basis accident through the accident analysis program. Liu et al. [9] analyzed the problems in the calculation of the fission product source term of M310/CPR1000, EPR, and AP1000 and modified the calculation process of the fission product source term. Jin et al. [10] used the modular accident analysis program-integrated severe accident analysis code (MAAPISAAC) to quantitatively evaluate the amount of radionuclides released into the environment following an interfacing system loss-of-coolant accident. The analysis results showed that the decontamination factor for nuclide groups, excluding inert gas, $\mathrm{Sb}$, and $\mathrm{Te}_{2}$ nuclide groups, was approximately 2.5 . Bahadir and Lindahl [11] used the nodal code SIMULATE to simulate the reactor core to calculate the node-wise burnup and the power of the target assembly (boron concentration, fuel temperature, moderator temperature, and power level) under different burnups. They found that SIMULATE- 5 can accurately describe the neutronic and thermal-hydraulic behavior of boiler water reactor and pressured water reactor (PWR) cores. Gera et al. [12] estimated the source terms of some postulated severe accident scenarios in the $220 \mathrm{MW}$ Indian pressurized heavy-water reactor. They found that the estimated source term and corresponding consequences were higher in reactor inlet header break cases than in reactor outlet header break cases. Ahn et al. [13] used MELCOR 2.2 and MAAP 5.04 to calculate the source terms of a PWR after a serious accident. They found that the dedicated mitigation strategy greatly decreased the environmental release of the fission product cesium. With regard to the evolution of severe accident and plant responses, both codes predicted the general trend of each base and mitigation scenarios. There are relatively few studies on the calculation of the weight of factors affecting the core source term in this type of literature. By calculating the radioactivity and photon source strength of actinides and fission products, the weight proportion of each factor was calculated by the multifactor variance analysis method [14]. It is of great significance to understand the importance of each influencing factor of the source term of the reactor core and to study the source term of the reactor under normal operations and serious accidents.

\section{Core Description}

The AP1000 core was selected as the research object. The basic parameters of the AP1000 fuel assembly [15] are listed in Table 1.

The influence of four factors: burnup, fuel enrichment, specific power of the reactor, and operation mode on the
TABLE 1: Basic parameters of AP1000 fuel assembly.

\begin{tabular}{lc}
\hline Name & Number \\
\hline Number of fuel assembly & 157 \\
Arrangement of fuel rods & $17 \times 17$ \\
Number of fuel rods per assembly & 264 \\
Fuel rod spacing (cm) & 1.3 \\
Cross-sectional size $(\mathrm{m})$ & $0.214 \times 0.214$ \\
Core fuel loading $(\mathrm{kg})$ & 96084 \\
Number of guide tubes in each assembly & 24 \\
Guide tube material & ZIRLO $^{\mathrm{TM}}$ \\
Central measuring tube size $(\mathrm{cm})$ & Internal diameter $(1.12)$ \\
& External diameter \\
& $(1.22)$ \\
\hline
\end{tabular}

source term of the reactor core was investigated. The values for each factor are listed in Table 2.

\section{Calculation Model}

3.1. Point Reactor Kinetics Model. In this study, the Oak Ridge Isotope Generation and Depletion Code (ORIGEN) was used for burnup calculations [16]. ORIGEN was developed by the Oak Ridge National Laboratory for nuclide ignition consumption, decay, and radioactive material treatment [17]. The input file specifications include a database of over 700 nuclides that are widely used in various types of reactors.

The ORIGEN program uses the point reactor kinetics model. According to the average neutron flux or the power of space and energy within a certain range and read in terms of various cross sections, decay, and other data from the database, we can calculate the accumulation and change of any nuclide in a given homogeneous material. In the program, a nonhomogeneous first-order ordinary differential equation [18] is used in the following equation:

$$
\frac{\mathrm{d} X_{i}}{\mathrm{~d} t}=\sum_{j=1}^{N} l_{i j} \lambda_{j} X_{j}+\phi \sum_{k=1}^{N} f_{i k} \sigma_{k} X_{k}-\left(\lambda_{i}+\phi \sigma_{i}+\gamma_{i}\right) X_{i}+F_{i},
$$

where $i(1,2,3, \ldots \ldots, N)$ is the number of nuclides; $X_{i}$ is the atom density of nuclide $i$; $l_{i j}$ is the fraction of radioactive disintegration by nuclide $j$ which leads to formation of nuclide $i ; \lambda_{\mathrm{i}}$ is the radioactive decay constant of nuclide $i$ (1/ s); $\phi$ is position- and energy-averaged neutron flux, $n /$ $\left(\mathrm{cm}^{2} \cdot \mathrm{s}\right) ; f_{i k}$ is the fraction of neutron absorption by nuclide $k$ which leads to formation of nuclide $i ; \sigma_{k}$ is the spectrumaveraged neutron absorption cross section of nuclide $k$; and $F_{i}$ is the continuous feed rate of nuclide $i$.

3.2. Neutron Fluence Calculation Model. In the ORIGEN2 program, the neutron flux is calculated from the power. For the sake of clarity, we assume that the power to be generated from the fuel is specified and that the flux must be calculated. The first approximation of instantaneous neutron flux at the beginning of the irradiation time step is shown in the following equation: 
TABLE 2: Values of each factor.

\begin{tabular}{lcccc}
\hline Factor & Fuel consumption $(\mathrm{MWd} / \mathrm{tU})$ & $\begin{array}{c}\text { Enrichment } \\
(\%)\end{array}$ & $\begin{array}{c}\text { Specific power } \\
(\mathrm{MW} / \mathrm{tU})\end{array}$ & Operation mode \\
\hline $\begin{array}{l}\text { Changes in fuel consumption } \\
(\mathrm{MWd} / \mathrm{tU})\end{array}$ & $\begin{array}{c}10,50,100,500,1000,10000,30000, \\
\text { and } 50000\end{array}$ & 4 & 40 & Continuous operation \\
Changes in enrichment (\%) & 30000 & $2,3,4$, and 5 & 40 & Continuous operation \\
Changes in specific power & 30000 & 4 & $20,30,40$, and 50 Continuous operation \\
$(\mathrm{MW} / \mathrm{tU})$ & 30000 & 4 & 40 & Intermittent operation \\
Changes in operation mode & & & 40
\end{tabular}

$$
\phi=\frac{6.242 \times 10^{18} \cdot P}{\sum_{i=1}^{N} X_{i}^{f} \cdot{\sigma_{i}^{f}}^{f} \cdot R_{i}}
$$

where $\phi$ is the instantaneous neutron flux $\left(\mathrm{n} \cdot \mathrm{cm}^{-2} \cdot \mathrm{s}^{-1}\right)$; $\mathrm{P}$ is the power (MW); $\mathrm{X}_{i}{ }^{f}$ is the amount of fissile nuclide $i$ in fuel (g.atom); ${\sigma_{i}}^{f}$ is the microscopic fission cross section for nuclide $i$, (barn); and $R_{i}$ is the recoverable energy per fission for nuclide $i(\mathrm{MeV} /$ fission).

3.3. Multivariate Analysis of Variance. The main function of multivariate analysis of variance [19] is to determine whether multiple factors have a significant influence on dependent variables through the process of hypothesis testing. The calculation model of the multivariate analysis of variance [20] is used in the following equation:

$$
\begin{gathered}
M S_{W}=\frac{S S_{W}}{d f_{W}}, \\
M S_{B}=\frac{S S_{B}}{d f_{B}}, \\
M S_{W}=\frac{M S_{B}}{M S_{W}},
\end{gathered}
$$

where $\mathrm{F}$ is the statistic; $M S_{B}$ is the variance between groups; $M S_{W}$ is the variance within groups; $S S_{B}$ is the sum of squares between groups; $S S_{W}$ is the sum of squares within groups; $d f_{B}$ is the degree of freedom between groups, $d f_{B}$ is $\mathrm{K}^{-1} ; \mathrm{K}$ is the number of groups; $d f_{W}$ is the degree of freedom within groups, $d f_{W}$ is $\mathrm{K}(\mathrm{n}-1)$; and $n$ is the number of levels in each group.

\section{Results}

4.1. Analysis of the Influence of Fuel Consumption. Fuel consumption was analyzed under the following conditions: specific power of $40 \mathrm{MW} / \mathrm{tU}$ with enrichment degree of $4 \%$ and continuous operation mode with the following operating times: 6 h, 30 h, 60 h, 300 h, 25 days, 250 days, 750 days, and 1250 days.

(1) Calculation of radioactivity: the radioactivity of actinides and fission products under different fuel consumptions is shown in Figure 1.

It can be seen that the radioactivity of actinides and fission products generally increased with the increase in fuel

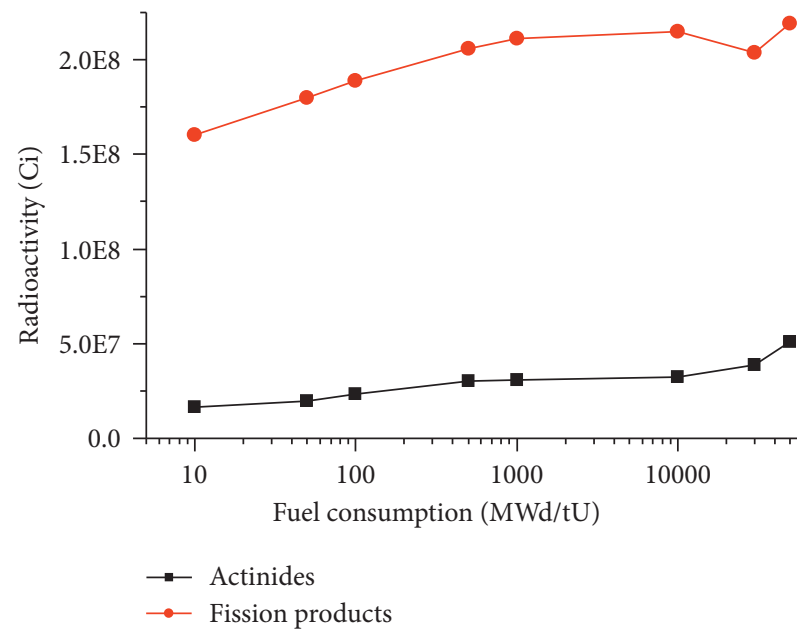

Figure 1: The radioactivity of actinides and fission products under different fuel consumptions.

consumption. However, after reaching $10000 \mathrm{MWd} / \mathrm{tU}$, the rising trend of fission product radioactivity slowed down, while that of actinides increased. The activity of fission products is one order of magnitude higher than that of actinides. Evidence has shown [21] that owing to the different half-lives, the radioactive decay law of various nuclides that change with fuel consumption is similar. The total amount of long-lived radionuclides increased with fuel consumption. In contrast, short-lived radionuclides were not very sensitive to changes in fuel consumption except in the initial accumulation stage. This is one of the reasons behind the different trends in the radioactivity of actinides and fission products.

(2) Calculation of photon source strength: the photon source strengths under different fuel consumptions are shown in Figure 2.

It can be seen that the photon source strength of each energy group increased with the increase in fuel consumption. Because of the variation of fission products and actinides with fuel consumption, the photon source strength of groups with energies of $1.36-1.80 \mathrm{MeV}$, $2.2-2.6 \mathrm{MeV}$, and $3.0-3.5 \mathrm{MeV}$ tend to decrease when the fuel consumption exceeds $10000 \mathrm{MWd} / \mathrm{tU}$. For the same fuel consumption, the photon source strength with low energy is more than 10 orders of magnitude greater than that with high energy. 


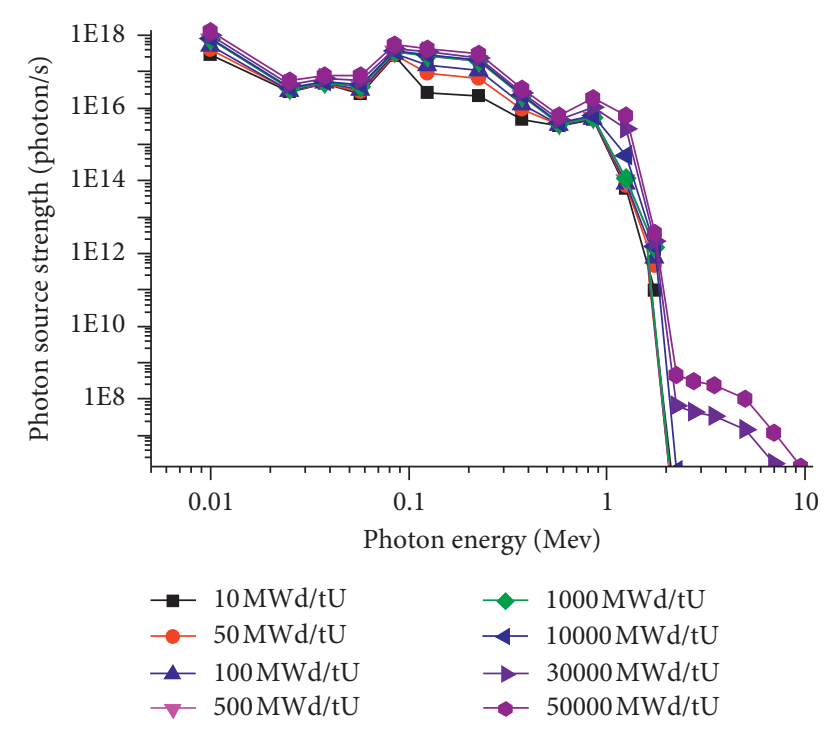

Figure 2: The photon source strength under different fuel consumption.

4.2. Analysis of the Influence of Enrichment. The influence of enrichment was analyzed under the following conditions: fuel consumption of $30000 \mathrm{MWd} / \mathrm{tU}$; a specific power of $4040 \mathrm{MW} / \mathrm{tU}$; continuous operation mode; and enrichment degrees of $2 \%, 3 \%, 4 \%$, and $5 \%$.

(1) Calculation of radioactivity: the radioactivity of actinides and fission products with different enrichments is shown in Figure 3.

It can be seen that the radioactivity of fission products and actinides decreased with the increase in enrichment. When the enrichment increased from $2 \%$ to $3 \%$, the radioactivity decreased significantly. When the enrichment increased from 3\% to 5\%, the radioactivity did not decrease. The main reason for this situation is that, under the same total fuel installed capacity, the $235 \mathrm{U}$ content at low enrichment was less, while at high enrichment, it was greater, which leads to changes in the radioactivity of actinides and fission products.

(2) Calculation of photon source strength: the photon source strengths under different enrichment are shown in Figure 4.

It can be seen that the photon source strength of each group of photons tended to decrease depending on the enrichment. Among them, the photon source strength of the group with energy greater than $2 \mathrm{MeV}$ decreased significantly. For the same enrichment, the lower the photon energy, the greater the photon source strength; the higher the photon energy, the smaller the photon source strength. The maximum values of both can reach 10 orders of magnitude.

4.3. Analysis of the Influence of Specific Power. The influence of specific power was analyzed under the following conditions: fuel consumption of $30000 \mathrm{MWd} / \mathrm{tU}$; enrichment of $4 \%$; continuous operation mode; and specific powers of $20 \mathrm{MW} / \mathrm{tU}, 30 \mathrm{MW} / \mathrm{tU}, 40 \mathrm{MW} / \mathrm{tU}$, and $50 \mathrm{MW} / \mathrm{tU}$.

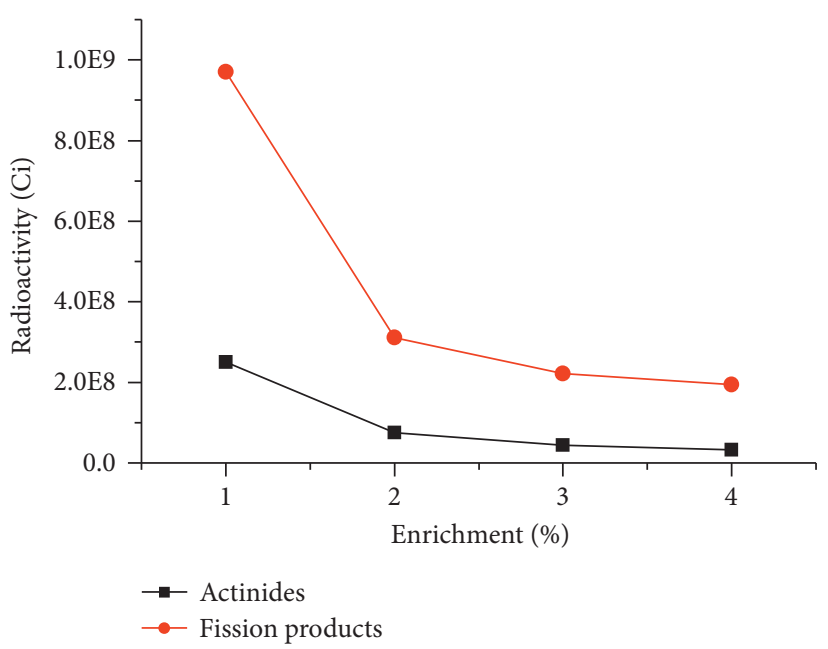

FIGURE 3: The radioactivity of actinides and fission products with different enrichments.

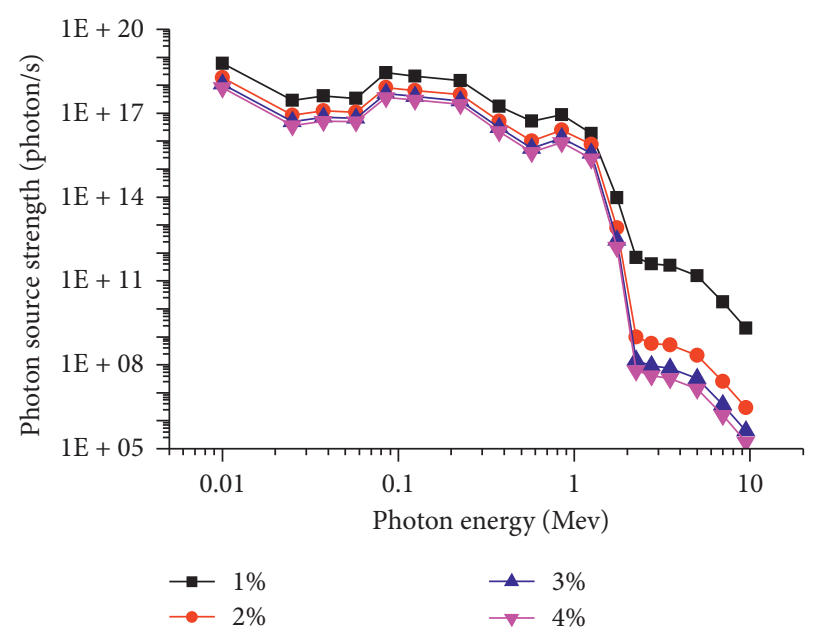

FIgURE 4: The photon source strengths under different enrichments.

(1) Calculation of radioactivity: the radioactivity of actinides and fission products at different specific powers is shown in Figure 5.

It can be seen that as the specific power increased, the activity of actinides and fission products increased gradually. However, the activity of fission products is several orders of magnitude higher than that of actinides. With the increase in specific power, the magnitude of change of fission products with specific power is higher than that of actinides. The radioactivity of fission products and actinides varied linearly with specific power, with a correlation coefficient of 1 .

(2) Calculation of photon source strength: the photon source strengths at different specific powers are shown in Figure 6 .

It can be seen that, in the low energy region, the higher the specific power, the stronger the photon source strength. In the high-energy region, the photon source strength was not affected by the specific power. At the same specific 


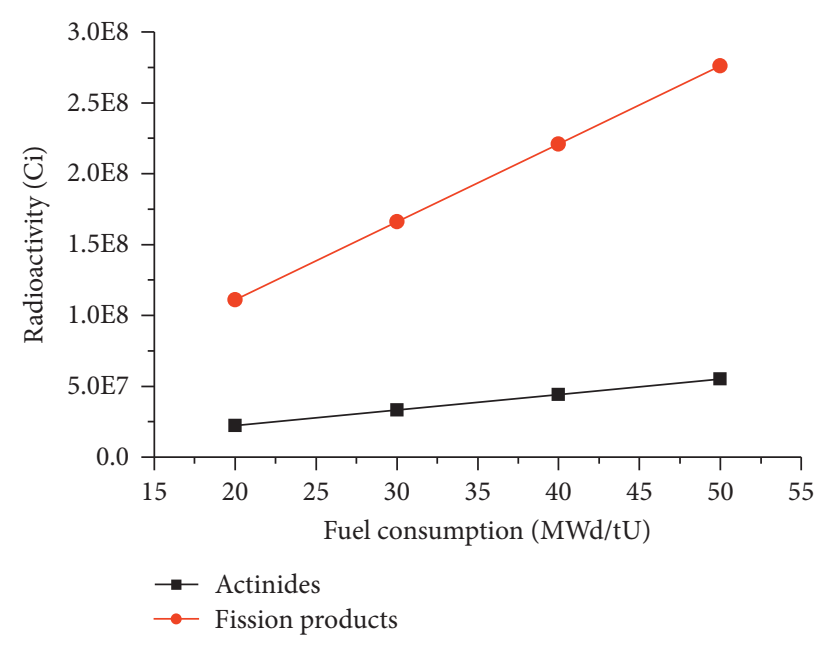

Figure 5: The radioactivity of actinides and fission products at different specific powers.

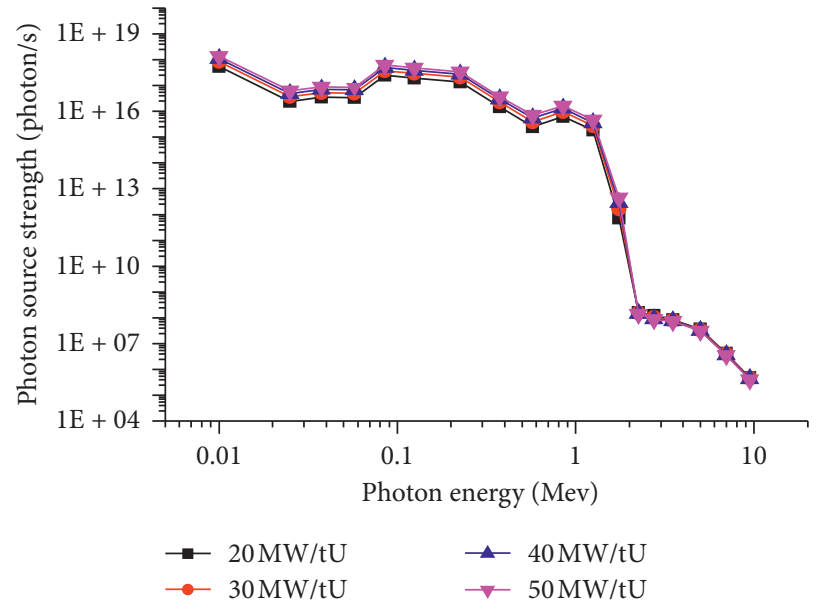

Figure 6: The photon source strengths under different specific powers.

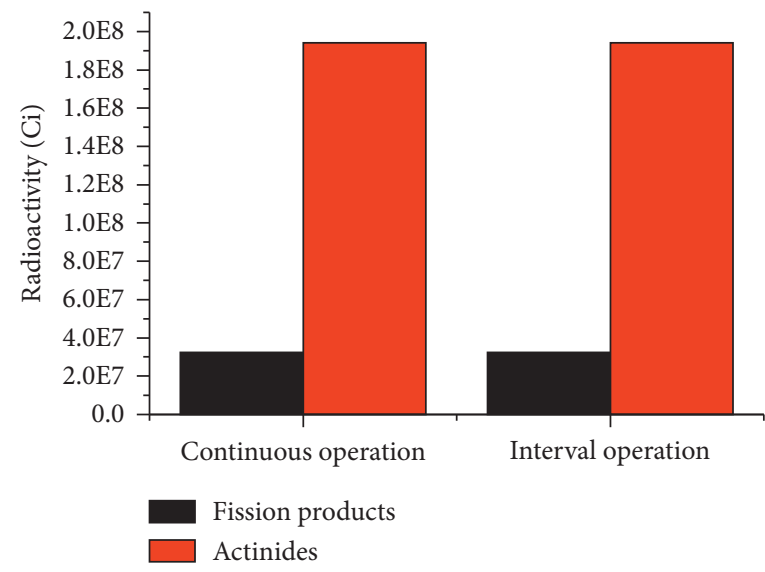

FIGURE 7: The radioactivity of actinides and fission products under different operation modes. 


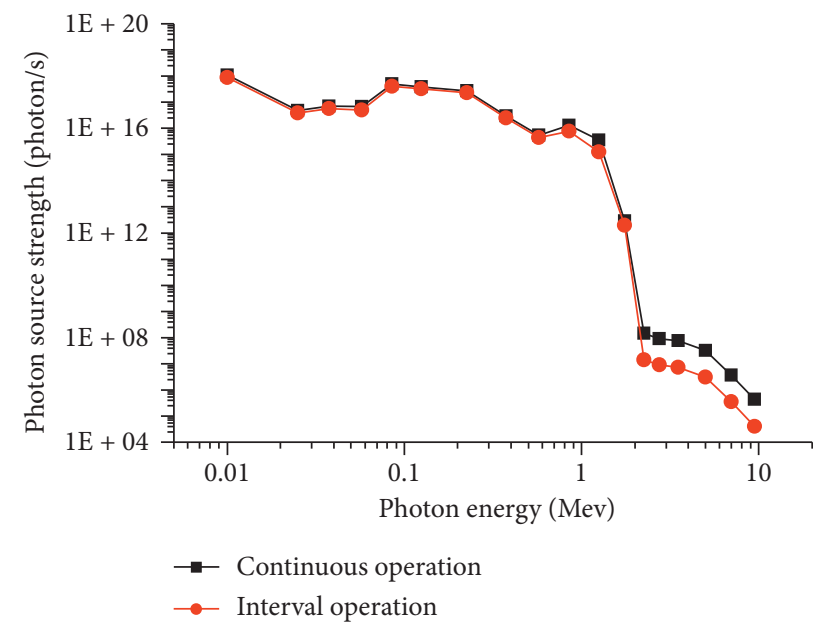

Figure 8: The photon source strengths under different operation modes.

TABLE 3: The orthogonal table of fuel consumption, specific power, and enrichment.

\begin{tabular}{lcccc}
\hline Number & & \multicolumn{2}{c}{ Factor } \\
Fuel consumption & Specific power & Enrichment & The activity of fission products \\
\hline 1 & 1000 & 40 & 0.03 & $2.188 \mathrm{E}+08$ \\
2 & 10000 & 10 & 0.03 & $5.883 \mathrm{E}+07$ \\
3 & 30000 & 20 & 0.03 & $1.513 \mathrm{E}+08$ \\
4 & 1000 & 20 & 0.04 & $1.070 \mathrm{E}+08$ \\
5 & 10000 & 40 & 0.04 & $2.132 \mathrm{E}+08$ \\
6 & 30000 & 10 & 0.04 & $5.414 \mathrm{E}+07$ \\
7 & 1000 & 10 & 0.05 & $5.306 \mathrm{E}+07$ \\
8 & 10000 & 20 & 0.05 & $1.038 \mathrm{E}+08$ \\
9 & 30000 & 40 & 0.05 & $1.898 \mathrm{E}+08$ \\
\hline
\end{tabular}

TABLE 4: The values of the influence factor $\mathrm{F}$.

\begin{tabular}{lccccc}
\hline Source & Sum sq. & d.f. & Mean sq. & $F$ & 1.21 \\
\hline X1 & 0.727 & 2 & 0.363 & -3.77 & 0.9009 \\
X2 & 11.683 & 2 & 5.841 & 52.73 \\
X3 & 348.46 & 2 & 174.23 & 0.3613 \\
Error & 6.608 & 2 & 3.304 & 0.0186 \\
Total & 367.478 & 8 & & \\
\hline
\end{tabular}

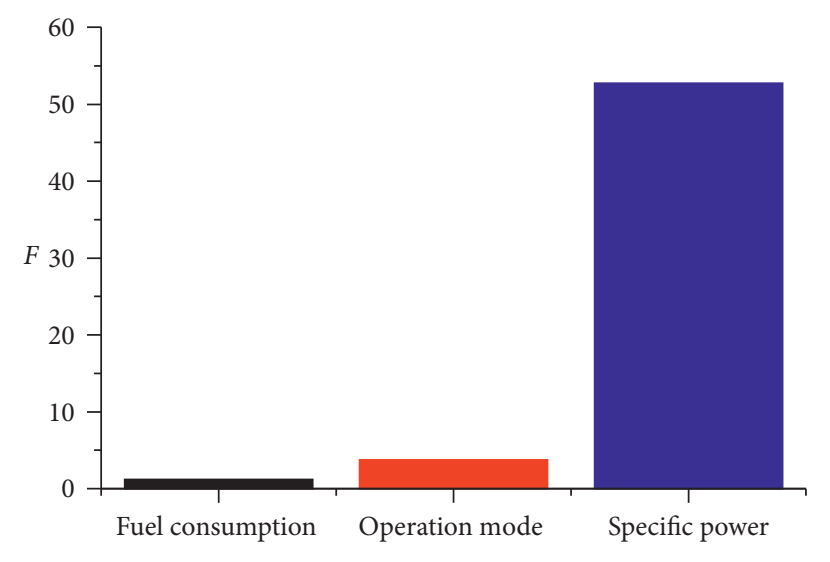

Figure 9: The influence factor $F$. 
power, the lower the energy, the greater the photon source strength; the higher the energy, the lower the photon source strength. The maximum values of both can reach 10 orders of magnitude.

4.4. Analysis of the Influence of the Operation Mode. The influence of the operation mode was analyzed under the following conditions: fuel consumption of $30000 \mathrm{MWd} / \mathrm{tU}$; specific power of $40 \mathrm{MW} / \mathrm{tU}$; enrichment degree of $4 \%$; and two operation modes: continuous and interval operations.

(1) Calculation of radioactivity: the radioactivity of actinides and fission products under different operating modes is shown in Figure 7.

It can be seen that the radioactivity of fission products and actinides did not change in both continuous operation and interval operation modes. This indicates that the operation mode has little effect on the activity.

(2) Calculation of photon source strength: the photon source strengths under different operation modes are shown in Figure 8.

It can be seen that the two operation modes have little effect on the photon source strength. Thus, under the same burnup and long operation time, the change in the operation mode will not have a significant impact on the photon source strength in the reactor.

4.5. Weight Calculation and Analysis. The weight of each impression factor was calculated and analyzed by multivariate analysis of variance. Section 4.4 shows that the operation mode does not affect the radioactivity and photon source strength of actinide nuclides and fission products; hence, the three factors of burnup, enrichment, and specific power were selected. Based on the data in Table 2, an orthogonal table of fuel consumption, specific power, and enrichment was established, as shown in Table 3.

According to Table 3, the multifactor analysis of variance program was completed, and Table 4 was obtained after calculation. The values of the influence factor $F$ of the operation results are shown in Figure 9.

Figure 9 shows that the accumulation of specific power to the core source term is the largest, far more than the other two factors. The enrichment degree is a negative correlation. Therefore, the type of reactor should be the main consideration in the selection of specific power to minimize the generation of the core source term in the reactor.

\section{Conclusions}

In this study, the key parameters for the calculation of the source terms for supercritical water-cooled reactors were selected. The ORIGEN2 code was used to simulate the radioactive activity and photon source strength under different fuel consumptions, enrichments, specific powers, and operation modes. The results show that the radioactivity of actinides and fission products increased with the increase in fuel consumption and decreased with the increase in enrichment. The radioactivity of fission products and actinides varied linearly with the specific power, with a correlation coefficient of 1 . Simultaneously, a multifactor analysis program was established to calculate the influence of various factors on the activity of fission products. It was found that the specific power was the most important factor, followed by the enrichment degree; fuel consumption was the least important.

\section{Data Availability}

The data used to support the findings of this study are available from the corresponding author upon request.

\section{Conflicts of Interest}

The authors declare no conflicts of interest in the publication of this paper.

\section{Authors' Contributions}

Tao Zhou and Peng Xu contributed to this work equally.

\section{Acknowledgments}

The authors thank Professor Xubo Ma (North China Electric Power University) for the support given in the simulation work. This research was funded by the National Key Research and Development Project (grant no. 2016YFC1402500), the Beijing Natural Science Foundation (grant no. 3172032), the Southeast University Discipline Promotion Plan (grant no. 1103007005), Double First-Class Construction Funds for Universities, and the Teacher Start Up Fund (grant no. 4003002071). The APC was funded by the National Key Research and Development Project (grant no. 2016YFC1402500).

\section{References}

[1] Z. H. Jia, Analysis and Research of Source Term Calculation, China Institute of Atomic Energy, Beijing China, 2004.

[2] F. Liu and Q. F. Zhu, "Source term analysis of minimum nuclear criticality accident," Atomic Energy Science and Technology, vol. 53, pp. 2204-2208, 2019.

[3] A. M. Wheeler, V. Singh, L. F. Miller et al., "Initial calculations for source term of molten salt reactors," Progress in Nuclear Energy, vol. 132, Article ID 103616, 2021.

[4] X. Sun, X. Cao, and X. Shi, "An improved simplified method of evaluating severe accident source term in the containment of ap1000," Annals of Nuclear Energy, vol. 113, no. 3, pp. 55-64, 2018.

[5] M. Lee and Y.-C. Ko, "Quantification of severe accident source terms of a westinghouse 3-loop plant," Nuclear Engineering and Design, vol. 238, no. 4, pp. 1080-1092, 2008.

[6] X. Liu, W. Peng, L. Wei, M. Lou, and G. Zheng, "A comprehensive study of the $14 \mathrm{C}$ source term in the $10 \mathrm{MW}$ hightemperature gas-cooled reactor," Radiocarbon, vol. 99, pp. 1-15, 2019.

[7] D. L. Fang, Y. F. Li, and D. Zhang, "Ab initio calculations of reactor antineutrino fluxes with exact lepton wave functions," Physics Letters B, vol. 813, Article ID 136067, 2021.

[8] H. R. Yang, L. Li, and J. Shen, "Accident source term analysis for qinshan phase II NPP project," Nuclear Power Engineering, vol. 24, no. z1, pp. 69-72, 2003. 
[9] X. H. Liu, L. Fang, and Z. W. Zhu, "Study on the framework of fission product source term for nuclear power plants," $A d$ vanced Materials Research, vol. 986-987, pp. 564-571, 2014.

[10] D. S. Jin, S. K. Kim, S. K. Han et al., "Best-estimate severe accident and source term analysis for an ISLOCA scenario of a CANDU-6 plant using the MAAP-ISAAC code," Nuclear Engineering and Design, vol. 358, Article ID 110443, 2020.

[11] T. Bahadir and S. Ö. Lindahl, "Studsvik's next generation nodal code SIMULATE-5," in Proceedings of the ANFM-2009 conference: Advances in Nuclear Fuel Management IV, Hilton Head Island, South Carolina, SC, USA, May 2009.

[12] B. Gera, M. Kumar, I. Thangamani et al., "Estimation of source term and related consequences for some postulated severe accident scenarios of Indian PHWR," Nuclear Engineering and Design, vol. 240, no. 10, pp. 3529-3538, 2010.

[13] K. I. Ahn, K. Lee, S. Lee et al., "Estimation of fission product source terms for the SGTR accident of a reference PWR plant using MELCOR and MAAP5," Nuclear Engineering and Design, vol. 371, Article ID 110967, 2021.

[14] X. M. C. Team, "MCNP-a general monte carlo N-particle transport code, version 5," Journal of Biological Chemistry, vol. 10, 2005.

[15] G. L. Song, D. L. Zhang, Q. Liu et al., "RELAP5/MOD3.4 calculation and model evaluation based on upper plenum entrainment experiment in AP1000," Annals of Nuclear Energy, vol. 138, pp. 107-143, 2020.

[16] Z. Foudil, B. Mohamed, and Z. Tahar, "Estimating of core inventory, source term and doses results for the NUR research reactor under a hypothetical severe accident," Progress in Nuclear Energy, vol. 100, pp. 365-372, 2017.

[17] A. G. Croff, A User's Manual for ORIGEN2 Computer Code (ORNL/TM-7175), Oak Ridge National Laboratory, Oak Ridge, TN, USA, 1980.

[18] J. J. Liu, J. C. Zhu, R. L. Wang et al., "Comparison analysis of Ito solution and analytical solution of probability distribution function of neutron number for point reactor stochastic dynamics equation," Nuclear Science and Engineering, vol. 39, no. 03, pp. 479-484, 2019.

[19] US Nuclear Regulatory Commission, "Calculational and dosimetry methods for determining pressure vessel neutron fluence," Regulatory Guide, vol. 1, p. 190, 2001.

[20] J. Fox, Applied Regression Analysis and Generalized Linear Models, SAGE Publications, England, UK, 2008.

[21] Z. S. Xie, Physical Theory and Calculation Method of Nuclear Reactor, Xi'an Jiaotong University Press, Xi'an, China, 1st edition, 2000. 